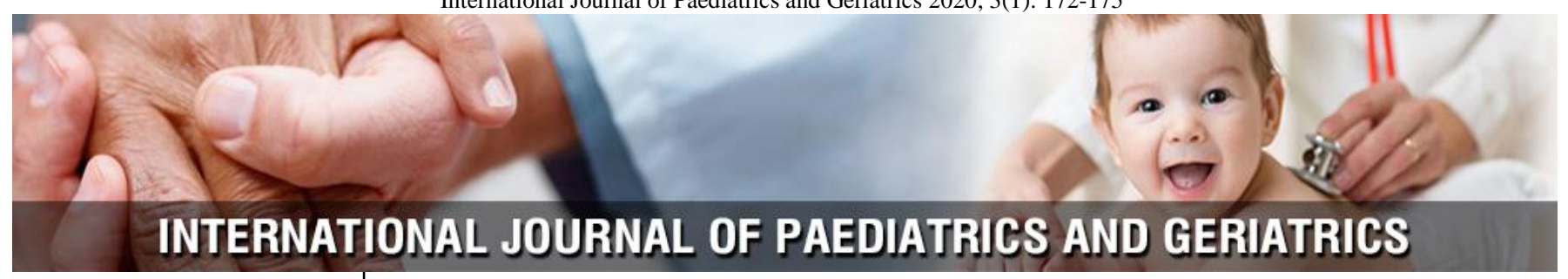

P-ISSN: 2664-3685

E-ISSN: $2664-3693$

www.paediatricjournal.com

IJPG 2020; 3(1): 172-175

Received: 26-11-2019

Accepted: 28-12-2019

Dr. Meghana Nannapaneni Department of Pediatrics, Kempegowda Institute of Medical Sciences, Bangalore, Karnataka, India

Dr. Poornima Shankar Department of Pediatrics, Kempegowda Institute of Medical Sciences, Bangalore, Karnataka, India

Dr. Abirami Meenakshi Chandrasekaran Department of Pediatrics, Kempegowda Institute of Medical Sciences, Bangalore, Karnataka, India
Corresponding Author: Dr. Meghana Nannapaneni Department of Pediatrics, Kempegowda Institute of Medical Sciences, Bangalore, Karnataka, India

\section{Maternal stress of cases in pediatric intensive care unit in Tertiary hospital Bangalore}

\author{
Dr. Meghana Nannapaneni, Dr. Poornima Shankar and Dr. Abirami \\ Meenakshi Chandrasekaran
}

DOI: https://doi.org/10.33545/26643685.2020.v3.i1c.78

\begin{abstract}
Background: Pediatric intensive care unit (PICU) is a highly stressful environment to most parents specifically mothers who are very sensitive. Knowledge of their stress helps us to plan counselling strategies for the suffering parents. The objectives were to identify common maternal stress factors during their child's critical illness and to examine the relationship of different variables with the stress. Methods: It was a prospective observational study done in PICU of a tertiary care medical college hospital in Bangalore. One hundred mothers of children (1 month to 15 years) admitted to PICU for at least 24 hours were interviewed using the Parental Stress Scale (PSS: PICU), which rates 22 factors on a scale from 1 to 5 . The demographic and clinical characteristics of children were also recorded and analysed statistically.

Results: The average parental stress score was 3.5. Parents of children who got admitted in PICU for the first time were more stressed The main causes of extremely stressful situations were the sight of other sick children in PICU sight of monitors \& equipment in PICU, their child being unresponsive, crisis in other children in the PICU.. Younger mother were more stressed than older mother, irrespective of the illness and clinical status. Age of the child, sex, socioeconomic status, urban/rural, did not vary stress levels, all had similar stress level (score>3). Among the procedures, majority (52\%) parents felt intravenous cannulation as more stressful followed by blood sampling (43\%).

Conclusions: For a mother, first PICU admission were more stressful. Socioeconomic status, age of children and residence did not affect level of stress. Many of these stress factors can be resolved and remedial steps can be undertaken to relieve these stressors.
\end{abstract}

Keywords: Maternal stress, Pediatric intensive care unit, Demographic factors

\section{Introduction}

Pediatric intensive care unit (PICU) is a highly stressful environment to most parents. Having one's child admitted to a PICU is difficult for parents, specifically mother The very criteria for admission to a PICU are frightening and can realistically prompt fear that their child could die or become severely disabled ${ }^{[1]}$.

The intensive care setting is a busy and frightening place dominated by sick children, medical personnel, advanced medical equipments, bright lights and shrill monitors. Initially, parents experience extreme levels of anxiety that approach near-panic level, followed by a reduction of anxiety in the following days ${ }^{[2]}$. One of the greatest stressors for mother in the PICU is the alteration or loss of the parental role, including physical separation, limited opportunities to care for the child, and no longer being the independent, primary decision maker in charge of the child's care ${ }^{[3]}$. mothers are required to make the transition from being mother of a well-child mother of an acutely ill child. This can be an extremely difficult process. In the past two decades, there were many studies on maternal stress which brought out various stressors like not knowing how to help their child, seeing their child frightened or in pain, and not being able to be with their crying child ${ }^{[4-6]}$. Knowledge of stress allows us to plan counselling strategies for the suffering mother.

Most of the studies done about maternal stress in PICU are from resource replete countries. Since the family preferences and clinician's delivery of care are affected by regional, religious and cultural influences, the data from India is different. There are only a few studies of this kind done in India ${ }^{[7,8]}$. Hence this study was taken to determine the clinical 
and sociodemographic factors leading to stress among parents whose children were admitted in PICU of a tertiary care hospital in Bangalore.

\section{Methods}

This was a prospective study done in the PICU Kims, a tertiary care centre in Bangalore for a period of 3 months from April 2018. The study was approved by institutional ethical committee. The PICU of this hospital is a dedicated 5-bed unit with a resident on round-the-clock duty. Almost all admissions to PICU are from the emergency room and pediatric wards and are unscheduled. All patients undergo cardiopulmonary monitoring in PICU. Every bed is equipped with an emergency cart providing items and medicines for resuscitation. The unit has a policy to permit one guardian to stay with the child in PICU, and parental counselling is done immediately after rounds.

Mother of children admitted in PICU for atleast 24 hours were invited to participate in the study. Parents with preexisting psychiatric illness, parents of children admitted with surgical illness, parents of children who died during or after PICU admission and those parents who refused to give consent were excluded from the study. Parents were included in the study after explaining about the objective of the study and after obtaining written consent from one of the parents. Those who were included in the study were given an information sheet containing details about the study, privacy details, and contact details of the primary investigator. In-depth interviews were conducted at the end of 24 hours, to facilitate the retrospective parental experiences. A detailed history and examination findings were entered in a predesigned proforma.

In this study the parental stress score in PICU (PSS: PICU) developed by Carter and Miles was used ${ }^{[9]}$. The PSS:PICU scale covers three broad areas: personal- family, situational and environmental stressors. The PSS: PICU is a 37 -item instrument designed to measure the overall stress response of parents to the potential sources of stress when their child is hospitalised in a PICU. Each item is scored from 1 (not stressful) to 5 (extremely stressful). The stressors are grouped under seven dimensions. Apart from the above stressors, scores were also taken in 22 items belonging to three categories, 8 items each in the category where stress is due to the experiences in PICU and where parents felt stressed by the way their baby looked to them and 6 items in the category where stress was related to things they see or hear. Maximum score for any parent was 110 , and minimum was 22. Socio economic status was calculated according to revised Kuppuswamy scale ${ }^{[10]}$. The data obtained were statistically analysed. Average stressor score was obtained for individual parent. Parents were categorised into two groups with stress score $<3$ and $>3$. Chi square test was applied to compare the two groups. These were correlated with the parental factors to find any statistical significance and correlation. Mean and standard deviation were computed, and the data were analysed by using SPSS 16.0 software (SPSS Inc. Chicago, IL, USA).

\section{Results}

A total of 100 Mothers were interviewed with The age of the mother varied from 20 to 44 years with 47 (47\%) being between 31-35 years and 36 (36\%) between 26-30 years. There was a patient male to female ratio of $1: 1$. The age distributions of patients were as follows: 17 infants, 54 from 1 to 5 years, 11 from 5 to 10 years and 18 patients between 10-15 years of age. Socio economic status was low in majority of enrolled. Sixty six $(66 \%)$ parents were from rural area whereas the rest $(34 \%)$ were from city limits. Eighty five children had their first PICU admission, while the rest had previous PICU admissions. Among the 100 cases, 15 had febrile seizure, 12 had pneumonia, 12 had seizure disorder, 11 had dengue, 8 had acute severe asthma, and others had other miscellaneous causes. During the PICU stay, 66 children were on iv fluids, 5 children were on inotropes and 3 were mechanically ventilated.

The average maternal stress score was 3.5. The main causes of extremely stressful situations were, the sight of their child being unresponsive; sight of monitors \& equipment in PICU, other sick children in PICU, crises in other children in the PICU (Table 1). Also, not being able to share baby with family and friends, not able to protect baby from painful procedures and not able to comfort/help their baby were also the causes of extremely stressful situations. Parents not having chance to be alone with their baby, nurses and other staff being closer to baby than parents themselves, being separated from their baby, and presence of large number of nurses and doctors who work around their baby did not cause much stress in parents. Parents of children who got admitted in PICU for the first time were more stressed $(P<0.001)$. Younger parents were more stressed than older parents, irrespective of illness and clinical status (Table 2).

Table 1: Mean scores in various stressors among parents

\begin{tabular}{|c|c|c|c|c|}
\hline \multirow{2}{*}{ Item } & \multirow{2}{*}{ Mean score } & \multicolumn{3}{|c|}{ Maternal score } \\
\hline & & 1-2 & 3 & $4-5$ \\
\hline A. How stressful are the following experiences? & (3.29) & & & \\
\hline 1. Being separated from your baby & 2.11 & 70 & 20 & 10 \\
\hline 2. Not being able to regularly care for your baby & 3.22 & 26 & 43 & 35 \\
\hline 3. Not having a chance to be alone with your baby & 2.44 & 50 & 38 & 12 \\
\hline 4. Not being able to share your baby with family and friends & 4.27 & 04 & 06 & 90 \\
\hline 5. Not being able to protect your baby from pain and painful procedures & 4.36 & 06 & 09 & 85 \\
\hline 6. Not being able to comfort/help your baby & 4.16 & 09 & 11 & 80 \\
\hline 7. The nurses and other staff seeming closer to the baby than you are & 2.26 & 60 & 32 & 08 \\
\hline 8. Not being able to hold your baby & 3.52 & 25 & 28 & 47 \\
\hline B. How stressed are you by the way your baby looks to you? & (3.63) & & & \\
\hline 9. Seeing your baby with tubes or IV lines on him/her & 3.50 & 04 & 46 & 50 \\
\hline 10. Seeing your child in pain & 3.86 & 10 & 30 & 60 \\
\hline 11. Having your child look afraid, be upset or cry a lot & 3.42 & 08 & 50 & 42 \\
\hline
\end{tabular}




\begin{tabular}{|c|c|c|c|c|}
\hline 13. Seeing a needle or tube put in your baby & 3.53 & 08 & 40 & 52 \\
\hline 14. Seeing your baby have problems breathing & 3.58 & 11 & 39 & 50 \\
\hline 15. Seeing your baby surrounded by machinery and having medical treatments & 3.48 & 09 & 43 & 48 \\
\hline 16. When your baby cannot respond to you & 4.16 & 05 & 14 & 81 \\
\hline C. How stressful are the things you might see or hear? & (3.76) & & & \\
\hline 17. Monitors and equipment in the room & 4.36 & 04 & 03 & 94 \\
\hline 18. The sudden sound of monitor alarms & 3.85 & 03 & 30 & 67 \\
\hline 19. The other sick children in the room & 4.13 & 01 & 14 & 85 \\
\hline $\begin{array}{l}\text { 20. Large number of nurses, doctors and other staff who work with your child } \\
\text { staff who work with your child }\end{array}$ & 2.76 & 55 & 09 & 36 \\
\hline 21. When other children in the hospital have a crisis? & 4.01 & 06 & 19 & 75 \\
\hline 22. The needs of other parents in the hospital & 3.48 & 03 & 54 & 43 \\
\hline
\end{tabular}

Table 2: Maternal stress score correlation with various factors.

\begin{tabular}{|c|c|c|c|c|c|}
\hline \multirow{2}{*}{ Factor } & & \multirow{2}{*}{ Total $(n=100)$} & \multicolumn{2}{|c|}{ Stress score } & \multirow{2}{*}{$P$ value } \\
\hline & & & $<3$ & $\geq 3$ & \\
\hline & $<25$ & 04 & 0 & 04 & \\
\hline & $26-30$ & 36 & 01 & 35 & \\
\hline \multirow[t]{4}{*}{ Age of mother (years) } & $31-35$ & 47 & 04 & 43 & 0.247 \\
\hline & $36-40$ & 10 & 0 & 10 & \\
\hline & $>40$ & 03 & 01 & 02 & \\
\hline & Class 1 & 01 & 0 & 01 & \\
\hline \multirow{3}{*}{ Socio-economic status } & Class 2 & 32 & 0 & 32 & \multirow{3}{*}{0.169} \\
\hline & Class 3 & 53 & 04 & 49 & \\
\hline & Class 4 & 14 & 02 & 12 & \\
\hline \multirow[t]{3}{*}{ Area } & Urban & 34 & 0 & 34 & 0.093 \\
\hline & Rural & 66 & 06 & 60 & \\
\hline & 1 & 16 & 01 & 15 & \\
\hline \multirow[t]{3}{*}{ Number of children } & $2-3$ & 77 & 05 & 72 & 0.739 \\
\hline & $4-5$ & 07 & 0 & 07 & \\
\hline & $<1$ & 17 & 02 & 15 & \\
\hline \multirow{2}{*}{ Age of patient (years) } & $1-5$ & 54 & 02 & 52 & \multirow{2}{*}{0.403} \\
\hline & $6-10$ & 11 & 01 & 10 & \\
\hline & $11-15$ & 18 & 01 & 17 & \\
\hline \multirow[t]{2}{*}{ Gender of child } & Male & 50 & 02 & 48 & 0.678 \\
\hline & Female & 50 & 04 & 46 & \\
\hline \multirow[t]{2}{*}{ PICU admission } & $1 \mathrm{st}$ & 85 & 0 & 85 & $<0.001 *$ \\
\hline & $>1$ & 15 & 06 & 09 & \\
\hline
\end{tabular}

Other additional factors were also analysed. Among the procedures, many $(52 \%)$ mothers felt i.v. cannulation was more stressful followed by blood sampling (43\%). In this study, 43 parents wanted more information about child's condition and 27 parents wanted more than one attendant to be allowed inside PICU.

\section{Discussion}

Admission of a child to PICU is one of the most stressful events for parents specifically mothers because of multiple factors like uncertain outcome, painful procedures and intense emotions. There are numerous studies from developed countries, which have emphasized the role of addressing parental stress and concerns in PICU in addition to routine care of patients ${ }^{[4-6,11-19]}$.

In a study on parental stressors from Ludhiana, India, Pooni et al. ${ }^{[8]}$, found that there is significant stress among parents of children admitted in PICU, where the average parental stress score was 3 . In the present study, the average parental stress score was 3.5, which points out there is significant stress.

In the present study, it is observed that the sight of their child being unresponsive, other sick children in PICU, crises in other children in the PICU contributed maximum to parental stress. We also noted that younger parents are more stressed. Similar observations were found by Pooni et al. ${ }^{[8]}$ In the present study, only 3 children were ventilated, and their parents were stressed equally as other parents. In a study done by Aamir et al., ${ }^{[7]}$ the main stressor for parental stress was intubation status of their children.

We found that sight and sound of PICU monitors and equipments contributed maximum to parental stress. Similar observations were found among a study on Hispanic parents where sight, sound and procedure were found to be most stressful in PICU environment ${ }^{[20]}$.

Socioeconomic status did not contribute to overall parental stress, as parents belonging to all class had significant stress. Parents from upper, middle and lower socioeconomic status were almost equally stressed.

Also, not being able to share baby with family and friends, not able to protect baby from painful procedures and not able to comfort/help their baby were also the causes of extremely stressful situations.

We noted that all the parents of children who got admitted in PICU for the first time are more stressed (score>3) compared to parents whose children had a previous PICU admission, which was not compared in any previous studies to the best of our knowledge. The limitations of this study 
include less number of very sick children, lack of follow up, authors did not analyze parents of those who expired during PICU stay. Most of the PICU of western countries have counsellors during parent counselling and more time is devoted for parent counselling, which is lacking in our setup.

\section{Conclusion}

There is significant stress that was noticed among parents of children admitted to PICU, and stress factors are different in different studies done elsewhere younger mother were more stressed. Age, gender, socioeconomic status, residential area, number and age of children did not affect level of stress. Many of these stress factors can be looked into and remedial steps can be taken to relieve some of these stressors. However further longitudinal studies from India are required to assess the deeper concerns and other psychological aspects of parents whose children are admitted in PICU.

\section{References}

1. Balluffi A, Kassam-Adams N, Kazak A, Tucker M, Dominguez T, Helfaer M. Traumatic stress in parents of children admitted to the pediatric intensive care unit. Pediatr Crit Care Med. 2004; 5:547-53.

2. Meyer E, Snelling L, Myren-Manbeck L. Pediatric intensive care: the parent's experience. AACN Clin Issues: Adv Pract Acute Crit Care. 1998; 9(1):64-74.

3. Fisher MD. Identified needs of parents in a pediatric intensive care unit. Crit Care Nurs. 1994; 14:82-90.

4. Miles MS, Carter MC. Coping strategies used by parents during their child's hospitalization in an intensive care unit. Child Health Care. 1985; 14:14- 21.

5. LaMontagne LL, Pawlak R. Stress and coping of parents and children in a pediatric intensive care unit. Heart Lung. 1990; 19:416-21.

6. Miles MS, Carter MC, Spicher C, Hassanein RS. Maternal and paternal stress reactions when a child is hospitalized in a pediatric intensive care unit. Issues Compr Pediatr Nurs. 1984; 7:333-42.

7. Aamir M, Mittal K, Kaushik JS, Kashyap H, Kaur G. Predictors of stress among parents in pediatric intensive care unit: a prospective observational study. Indian $\mathbf{J}$ Pediatr. 2014; 81(11):1167-70.

8. Pooni PA, Singh D, Bains HS, Misra BP, Soni RK. Parental stress in a paediatric intensive care unit in Punjab, India. J Paediatr Child Health. 2013; 49:204- 9.

9. Carter MC, Miles MS. The parental stressor scale: pediatric intensive care unit. Matern Child Nurs J. 1989; 18:187-98.

10. Kumar N, Gupta N, Kishore J. Kuppuswamy's socioeconomic scale: updating income ranges for the year 2012. Indian J Public Health. 2012; 56(1):103-4.

11. Kasper JW, Nyamathi AM. Parents of children in the pediatric intensive care unit: what are their needs? Heart Lung. 1988; 17:574-81.

12. Nizam M, Norzila MZ. Stress among parents with acutely ill children. Med J Malaysia. 2001; 56:428- 34.

13. Needle JS, O'Riordan M, Smith PG. Parental anxiety and medical comprehension within 24 hours of a child's admission to the pediatric intensive care unit. Pediatr Crit Care Med. 2009; 10(6):668- 74.

14. Graves JK, Ware ME. Parents' and health professionals' perceptions concerning parental stress during a child's hospitalization. Child Health Care. 1990; 19:37-42.

15. Haines C, Perger C, Nagy S. A comparison of stressors experienced by parents of intubated and non-intubated children. J Adv Nurs. 1995; 21:350-5.

16. Eberly TW, Miles MS, Carter MC, Hennessey J, Riddle I. Parental stress after the unexpected admission of a child to the intensive care unit. CCQ. 1985; 8:57-65.

17. Miles MS, Mathes M. Preparation of parents for the ICU experience: what are we missing? Child Health Care. 1991; 20:132-7.

18. Scott LD. Perceived needs of parents of critically ill children. J Soc Pediatr Nurs. 1998; 3:4-13.

19. Board R, Ryan-Wenger N. Stressors and stress symptoms of mothers with children in the PICU. J Pediatr Nurs. 2003; 18(3):195-202.

20. Rei RM, Fong C. The Spanish version of the parental stressor scale: pediatric intensive care unit. J Pediatr Nurs. 1996; 11(1):3-9. 